\title{
Increasing exploration efficiency with SOLSA Expert System
}

M. Le Guen ${ }^{1}$, Y. El Mendili ${ }^{4}$, C. Duee ${ }^{2}$, B. Orberger ${ }^{10}$, H. Pilliere $^{5}$, S. Delchini ${ }^{2}$, C. Bessin ${ }^{1}$, E. Borovin ${ }^{7}$, A. Kanzari ${ }^{1}$, L. Lutterotti ${ }^{7}$, M. Bortolotti ${ }^{7}$, M. Secchi ${ }^{7}$, D. Chateigner ${ }^{3}$, A. El Mendili ${ }^{5}$, T. Lefevre ${ }^{5}$, S. Grazulis $^{6}$, G. Mariotto ${ }^{8}$, H. Nolte ${ }^{9}$, T. Teerlink ${ }^{9}$

${ }^{1}$ Eramet Ideas; ${ }^{10}$ University Paris Sud; ${ }^{2}$ BRGM; ${ }^{3}$ CRISMAT-ENSICAEN; ${ }^{4}$ ESICT; ${ }^{5}$ Thermo Fisher Scientific; ${ }^{6}$ Vilnius University of Technology; ${ }^{7}$ University of Trento; ${ }^{8}$ University of Verona; ${ }^{9}$ Eijkelkamp SonicSampDrill

\section{Summary}

SOLSA is the first automated expert system for on-site cores analysis. The scope is to provide a prototype to be an innovative and necessary tool for geo-metallurgy, in order to optimize the valorization of the ore. The Expert System consists in the combination of an integrated drilling rig providing cores of high quality, an automated scanner and phase identification software, developed for nickel laterites and bauxites but usable as well in other sectors. SOLSA combines non-destructive sensors and the whole system is driven by an innovative, user-friendly and intelligent software. SOLSA provides more complete information while optimizing the exploration stage, with a significant reduction of costs and return time. Such objective involves, in the first place, to fast, cheaper and systematic acquisition of the data needed for optimizing the process. The adding value takes place first at the exploration or grade control stage, furnishing systematic characterization and regionalization of the different types of ore. Then such information can be used for improving the ore scheduling at the mining and processing stages, toward improving the recovery and efficiency of the processing. 


\section{Introduction}

SOLSA (Sonic On-Line drilling and Sampling Analysis) is an ambitious project funded by the European Union that started in 2016. It aims to develop and deliver a combined integrated system prone to use in the field of mineral exploration. The goal is to provide an efficient tool for geo-metallurgy in delivering on-line real time mineralogical and chemical analysis of drill cores, leading to fast mining and processing decisions from the exploration stage.

The prototype SOLSA Expert System includes different modules consisting in a sonic drilling system, a core scanner and a combined XRD-XRF-Raman system. All instruments are driven and combined by software, specifically developed during the project, and connected to open database where the data obtained are stored and interpreted.

In a first stage, the prototype has been set up for nickel laterite environment and a library containing spectra from minerals classically present in such rocks have been entered in the database. In a second stage, when the decision was taken to perform the first field tests in a bauxite mine, the library has been completed with additional spectra from minerals usually found in bauxite environment. Indeed, the Expert System can be used in any other geological context with limited adjustments.

The present paper shortly describes the concept of the SOLSA Expert System and, based on an example in nickel laterite, the expected consequences of its use in the exploration or grade control stage for raw material industries.

\section{Concept of SOLSA Expert System}

The SOLSA Expert System is composed of three main modules formally named DRILL, IDENTIFICATION (ID) and SOFTWARE-DATABASE. A laboratory version ID1 was assembled during the first year of the project in order to test and choose the best configuration and parameters of the on-field version ID2. Such tests have demonstrated that it was essential to split the module ID2 in two sub-modules ID2A and ID2B (Fig. 1), in order to ensure that it runs as fast as the drill rig.

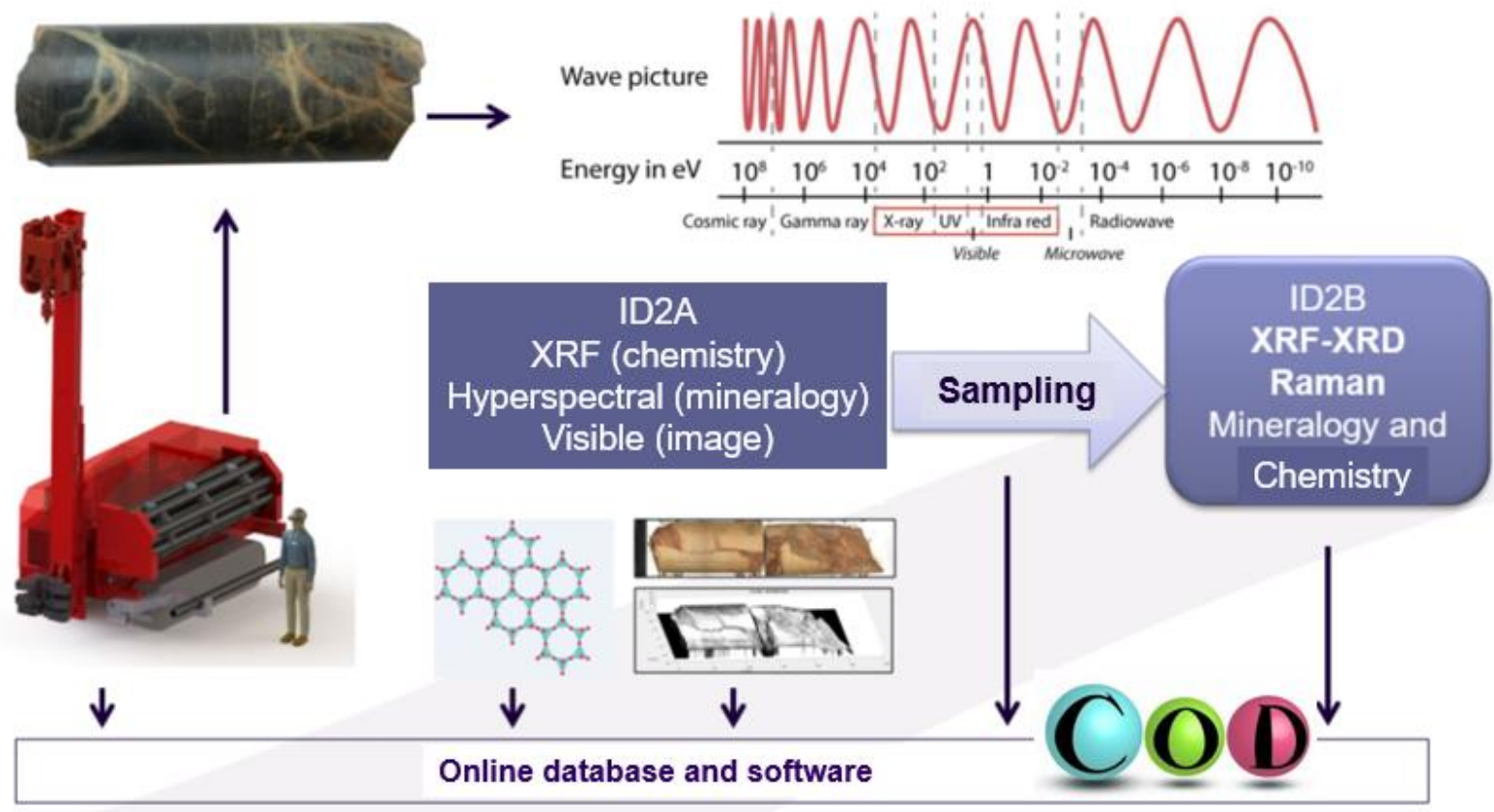

Figure 1. Schema illustrating the general concept of the SOLSA Expert System

DRILL: The CompactRotoSonic-SOLSA (CRS-S) and its add-ons represent the start of a new generation of sonic drilling rigs and is a result of over 100 years of soil sampling experience. Their development is focused on obtaining representative drill cores in the most challenging heterogeneous geological circumstances out there, in a perfectly safe, ergonomic and economic manner. In addition, 
the rig is fully connected to the database and can send interesting geotechnical information deduced from the rock penetration rate. The added value of the SOLSA Expert System starts at the core (Orberger et al., 2017).

IDENTIFICATION (ID2): Designed and built as a solid and robust machine to operate on-site, it is composed of the ID2A scanner and the ID2B benchtop combined analysis, is mounted in a ruggedized mobile laboratory trailer designed to travel with the drill rig on the exploration site. The concept is based on a large spectral analyze of the drill core, from X-Ray (diffraction and fluorescence), to infrared wavelength. This extended investigation provides the chemical and mineralogical analyses of the drill core either as a whole or on identified regions of interest, depending both on the target speed of analyses and on the strategy of sampling in use in the company.

SOFTWARE \& DATABASE: The SOLSA EXPERT SYSTEM includes independently developed software dedicated to the execution of different tasks. Recorded data are stored on- and offline, databases are created and updated. The SOLSA software and database are linked and interacting with open databases (e.g. COD, ROD).

\section{Analyses on serpentinized harzburgite}

During measurement on ID2A, data acquired by each of the sensors are automatically synchronized and integrated (data fusion) into a unique mega-file (Fig. 2). This is performed using a 3D space-time model in metric units defined by the data grid of the profilometer. The fused data are stored in the SOLSA cloud (Bui et al., 2018). This step is essential for identifying ROIs (regions of interest) with respect to the definition given by the geologist (Duée et al., 2019). The time of the scanner analyses respects the target of $6 \mathrm{~m} / \mathrm{h}$ given by the performance of the drill rig in nickel laterite environment.

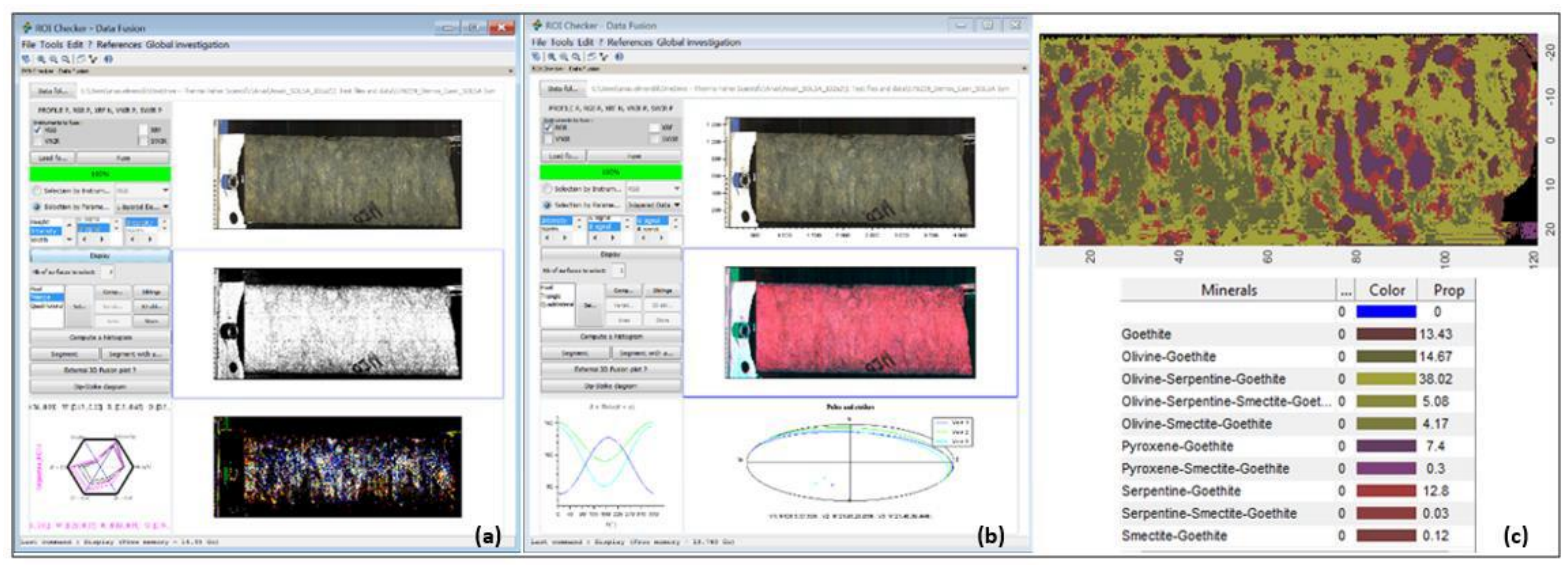

Figure 2. Example of automated analysis program, (a) N-parametric display, zone selection, segmentation, cross-correlation; (b) Dip-Strike (pole density diagram, structural calculation); (c) mineral mapping and proportions estimated from hyperspectral processing.

Note that this example perfectly reflects the case of mineral associations where pure phases cannot be easily individualized. Different mineral associations may constitute different ROIs which can be sampled for being more precisely analyzed with ID2B. The sampling procedure of ROIs will depend on the protocol in use in the company and on the requested scale of analyze.

In the present study, the ROIs were prepared and powered for combined analysis and quantification by Rietveld method in the minilab ID2B. Both chemical elements and mineral phases (Fig. 3) are determined (Bortolotti ${ }^{1}$ et al., 2017; Lutterotti et al., 2019), using XRF and XRD techniques as well as Raman (El Mendili ${ }^{1}$ et al., 2019; Bortolotti ${ }^{2}$ et al., 2019). 
All data provided by the combined instruments are interconnected with an open access database which has been implemented for hyperspectral data, spectral data and Raman data (Secchi et al., 2018; El Mendili ${ }^{2}$ et al., 2019).
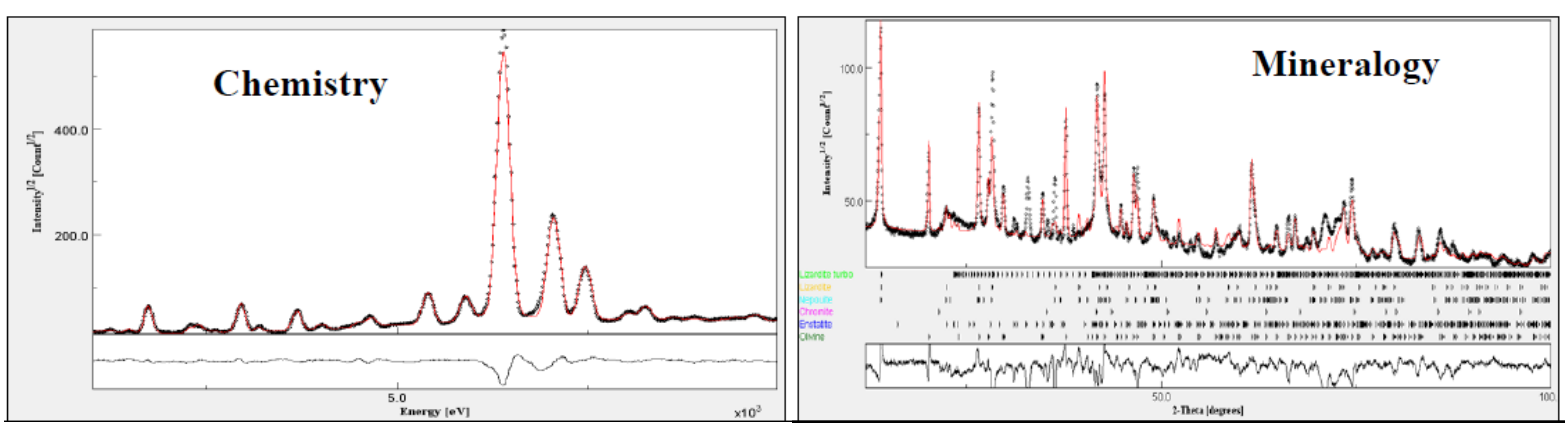

Figure 3. Combined analysis for quantification by Rietveld method on power. Left: chemistry; right: mineralogy. Results give quantitative proportion of chemical elements and phases.

A large amount of variable data (e.g. coordinate, geotechnical parameters, geochemical \& mineralogical information) is produced by the drill and different sensors composing the SOLSA expert system. To avoid errors, data are always collected in a strictly ordered manner (under a pre-defined schema) and are stored in a SQL database in a central place to be easily managed (Grazulis et al., 2018).

\section{Conclusions}

The different tests performed on laterite and bauxite samples, and more generally on soils resulting from a weathering process, show that the combination of different analytical techniques is essential for detecting the phases constituting mineral associations. Indeed, silicates may be more or less destroyed and replaced by neo-formed minerals, complicating their identification and quantification. For that reason, all results obtained on the prototype ID2 have been validated by analyses performed in laboratory on the same samples.

SOLSA Expert System can deliver in real time the chemical, mineralogical and morphological information on cores of high quality provided by the drill rig. The main consequence is a clear increase in exploration efficiency, by enlarging the field of information data while reducing cost and time of the campaign. In addition, the speed of analyses return allows for short-term decision making, in exploration but also in grade control stage, with for instance scheduling and orienting ore fluxes from mine operation to processing unit.

\section{Acknowledgements (Optional)}

This project has received funding from the European Union's Horizon 2020 research and innovation program under grant agreement No 689868. Research and development have been performed by members of the consortium SOLSA, employees of Eramet Ideas, SLN-Le Nickel, Eijkelkamp SonicSampDrill, INEL-ThermoFisher Scientific, BRGM, CNRS-CRISMAT, Universities of Caen, Trento, Verona, Vilnius and TU Delft.

\section{References}

Bortolotti ${ }^{1}$, M., Lutterotti L., and Pepponi G., (2017). Combining XRD and XRF analysis in one Rietveld- like fitting. Powder Diffraction, 32(S1): S225-S230

Bortolotti $^{2}$, M., Lutterotti, L., Borovin, E. and Martorelli D., (2019). Combined XRD-XRF cluster analysis for automatic chemical and crystallographic surface mappings. Powder Diffraction, pages 1-6.

Bui, T., Orberger, B., Blancher, S., Mohamed-Djafari, A., Pillière, H., Salaün, A., Bourrat, X., Maubec, N., Lefevre, T., Rodriguez, C., Grazulis, S., Duée, C., Harang, D., Wallmach, T., Chateigner, D., Le 
Guen, M. (2018). Building a Hyperspectral library and its incorporation Into sparse unmixing for mineral identification. Proceedings ICARSS (International Remote Sensing conference), Valencia Spain, July; IGARSS 2018-2018 IEEE International Geoscience and Remote Sensing Symposium, 2018, pp. 4261-4264.

Duée, C., Orberger, B., Maubec, N., Laperche, V., Capar, L., Bourguignon, A., Bourrat, X., El Mendili, Y., Gascoin, S., Chateigner, D., Rodriguez, C., Salaün, A., Le Guen, M., Mariotto, G., Giarola, M., Kumar, A., Daldasso, N., Zanatta, M., Lutterotti, L., Borovin, E., Bortolotti, M., Secchi, M., Montagna, M., Pillière, H., Lefevre, T., Eijkelkamp, F., Nolte, H., Koert, P., Grazulis, S., Trotet, F., Kadar, M., Devaux K. (2019). Impact of heterogeneities and surface roughness on pXRF, pIR, XRD and Raman analyses: Challenges for on-line-real-time combined mineralogical and chemical analyses on drill cores and implication for "high speed" Ni-laterite exploration. Journal of Geochemical Exploration: Special Volume on Nickel laterite, Journal of Geochemical Exploration 198 1-17.

El Mendili ${ }^{1}$, Y., Chateigner, D., Orberger, B., Gascoin, S, Bardeau, JF., Petit, S., Le Guen, M., Pillière, H. (2019). Combined XRF, XRD, SEM-EDS, and Raman analyses on serpentinized harzburgite (Nickel Laterite Mine, New Caledonia): Implications for Exploration and Geometallurgy. ACS Earth and Space Chemistry. 3, 10, 2237-2249; DOI: 10.1021/acsearthspacechem.9b00014.

El Mendili², Y., Vaitkus, A., Merkys, A., Gražulis, S., Chateigner, D., Mathevet, F., Gascoin, S., Petit, S., Bardeau, J-F., Zanatta, M., Secchi, M., Mariotto, G., Kumar, A. Cassetta, M., Lutterotti L., Borovin, E., Orberger, B, Le Guen, M. (2019). ROD project: First interconnected Raman-XRD open-access database for material identification worldwide, Journal of Applied Crystallography, 52, 618-625, doi.org/10.1107/S1600576719004229.

Gražulis, S.; Merkys, A. \& Vaitkus, A. Crystallography Open Database (COD). in Handbook of Materials Modeling, Springer International Publishing, 2018, 1-19, DOI: 10.1007/978-3-319-429137_66.

Lutterotti, L., Pilliére, H., Fontugne, C., Boullay, P., and Chateigner, D., (2019). Full-profile searchmatch by the Rietveld method. J. Appl. Cryst., 52(3), 587-598.

https://doi.org/10.1107/S160057671900342X.

Orberger, B., Eijkelkamp,.F. Le Guen, M. (2017). The importance of high-quality drill cores for geometallurgy. 14th SGA Biennial Meeting, Quebec City, Canada, August 20-23. Mineral resources to discover, Proceedings. V.3, 1221-1223.

Secchi, M., Zanatta, M., Borovin, E., Bortolotti, M., Kumar, A., Giariola, M., Sanson, A., Orberger, B., Daldasso, N., Gialanella, S., Mariotto, G., Montagna, M., Lutterotti, L. (2018). Mineralogical investigations using XRD, XRF and Raman Spectroscopy in a combined approach. Journal of Raman Spectroscopy, 1-8. https://doi. org/10.1002/jrs.5386. 